\title{
Internet Access and Usage Among Stroke Survivors and Their Informal Caregivers: Cross-sectional Study
}

Imama Ali Naqvi ${ }^{1}$, MD; Tahani Casameni Montiel ${ }^{2}, \mathrm{BBA}$; Yazan Bittar ${ }^{3}, \mathrm{BA}$; Norma Hunter ${ }^{4}, \mathrm{MA}$; Munachi Okpala ${ }^{5}$, MBA, MSN; Constance Johnson ${ }^{6}, \mathrm{RN}, \mathrm{PhD}$; Mark G Weiner ${ }^{7}$, MD; Sean Savitz ${ }^{5}$, MD; Anjail Sharrief ${ }^{5}$, MPH, MD; Jennifer Elizabeth Sanner Beauchamp ${ }^{8}, \mathrm{RN}, \mathrm{PhD}$

\footnotetext{
${ }^{1}$ Division of Stroke and Cerebrovascular Diseases, Department of Neurology, Columbia University Irving Medical Center, New York, NY, United States

${ }^{2}$ Department of Nursing Research, Cizik School of Nursing, The University of Texas Health Science Center at Houston, Houston, TX, United States

${ }^{3}$ Lewis Katz School of Medicine, Temple University, Philadelphia, PA, United States

${ }^{4}$ Department of Neurology, Institute for Stroke and Cerebrovascular Disease, The University of Texas Health Science Center at Houston, Houston, TX, United States

${ }^{5}$ Department of Neurology, Institute for Stroke and Cerebrovascular Disease, McGovern Medical School, The University of Texas Health Science Center at Houston, Houston, TX, United States

${ }^{6}$ Department of Nursing Research, Cizik School of Nursing and School of Bioinformatics, The University of Texas Health Science Center at Houston, Houston, TX, United States

${ }^{7}$ Department of Population Health Sciences, Weill Cornell Medicine, New York, NY, United States

${ }^{8}$ Department of Nursing Research, Cizik School of Nursing, Institute for Stroke and Cerebrovascular Disease, The University of Texas Health Science Center at Houston, Houston, TX, United States
}

\section{Corresponding Author:}

Imama Ali Naqvi, MD

Division of Stroke and Cerebrovascular Diseases

Department of Neurology

Columbia University Irving Medical Center

$710 \mathrm{~W} 168$ th St

6th Fl, Ste 650

New York, NY, 10032

United States

Phone: 12123058253

Email: ian2108@cumc.columbia.edu

\section{Abstract}

Background: Web-based interventions have shown promise for chronic disease management but have not been widely applied to populations with stroke. Existing barriers may inhibit the adoption of web-based interventions among stroke survivors and necessitate the involvement of informal caregivers. However, limited information is available on internet accessibility and usability among stroke survivors and their caregivers.

Objective: This study aims to investigate internet access and usage in a cohort of stroke survivors and their caregivers.

Methods: A cross-sectional survey was conducted with 375 participants (248 stroke survivors and 127 caregivers). Descriptive statistics were generated using cross-tabulation. Comparisons with categorical data were conducted using the chi-square test, whereas the Mann-Whitney $U$ test was used for comparisons involving ordinal variables.

Results: Overall, 86.1\% (323/375) of the participants reported having internet access. Caregivers were more likely than stroke survivors to access the internet $\left(\mathrm{N}=375, \chi_{1}^{2}=18.5, P<.001\right)$ and used text messaging $\left(\mathrm{n}=321, \chi^{2}{ }_{1}=14.7, P<.001\right)$. Stroke survivors and caregivers with internet access were younger than stroke survivors and caregivers without internet access. The highest number of participants who reported internet access were non-Hispanic White. Smartphones were the most common devices used to access the internet. Email was the most common type of internet usage reported. Patients who survived for $>12$ months after a stroke reported higher internet access than those who survived $<3$ months $(P<.001)$. The number of hours per week spent using the internet was higher for caregivers than for stroke survivors $(P<.001)$. 
Conclusions: Future feasibility and acceptability studies should consider the role of the informal caregiver, participant age, race and ethnicity, the use of smartphone apps, email and text correspondence, and the amount of time elapsed since the stroke event in the design and implementation of web-based interventions for populations with stroke.

(JMIR Form Res 2021;5(3):e25123) doi: 10.2196/25123

\section{KEYWORDS}

internet access; stroke; caregivers; surveys; questionnaires; mobile phone

\section{Introduction}

\section{Background}

In the United States, 795,000 people experience stroke annually [1]. Although improvements in the acute management of stroke have led to a decline in associated mortality, stroke-related morbidity leads to chronic disability in approximately half of all stroke survivors [2]. Comprehensive poststroke interventions should consider common stroke sequelae, including functional disabilities (eg, limb paralysis and sensory disturbances), speech disabilities (eg, aphasia), emotional disturbances (eg, poststroke anxiety and depression), and cognitive impairments (eg, impaired memory) [1]. Mobility is reduced in more than half of all stroke survivors aged $\geq 65$ years [3]. Difficulty in producing and understanding speech, known as aphasia, occurs in an estimated $25 \%-40 \%$ of stroke survivors [4]. The prevalence of poststroke anxiety and depression ranges from $21 \%$ to $29 \%$ and from $29 \%$ to $31 \%$, respectively [5-7]. Stroke is the second most common cause of cognitive impairment and dementia, with approximately $30 \%$ of stroke survivors experiencing cognitive impairment [8] or dementia [9]. Despite the complex needs of stroke survivors, poststroke care systems are inadequate. Stroke survivors may have limited access to outpatient care because of impaired mobility, limited access to transportation, and lack of support [10]. Most stroke survivors are discharged home from the hospital and receive care provided primarily by unprepared informal caregivers (eg, spouses and family members) [11,12]. Measures that expand access to poststroke care and comprehensively address the challenges that stroke survivors and their caregivers encounter are needed [13].

Web-based telehealth interventions have been found to be effective for acute stroke care, potentially beneficial for extended neurology care in rural areas [14], and cost-effective in stroke and dementia populations $[15,16]$.

\section{Purpose}

Although a number of studies have examined internet access and usage among populations other than those with stroke (eg, patients with diabetes) [17], studies are needed to determine the feasibility and acceptability of web-based interventions across diverse stroke populations with complex disabilities and various levels of ability [18]. Uncertainties remain regarding the implementation of web-based interventions, including suitable stroke survivors and necessary stroke survivor support structures [19], as well as the role of the caregiver. Only $67 \%$ of US adults aged $\geq 65$ years reported internet access compared with $44 \%$ of adults aged $\geq 80$ years [20]. The lower rates of internet access with advancing age present an additional challenge, as an estimated three-fourths of all strokes occur in adults aged $\geq 65$ years [21] and $17 \%$ of all strokes occur in adults aged $>85$ years [22]. Non-Hispanic Black and Hispanic US adults are less likely than non-Hispanic White adults to have access to the internet in their home environment [23]. The highest increase in stroke prevalence $(29 \%)$ is estimated to be reported among Hispanic men [1], and known racial and ethnic disparities occur in almost every aspect of stroke care [24]. To develop appropriate and accessible web-based interventions for stroke survivors and caregivers, we must fully understand these digital disparities within the context of stroke survivorship. Therefore, the purpose of our study was to investigate internet access and usage in a cohort of stroke survivors and their caregivers.

\section{Methods}

\section{Design and Sampling}

This was an observational study of cross-sectional survey data collected from a convenience sample of stroke survivors and their caregivers from 2 large metropolitan areas: Houston, Texas, and Philadelphia, Pennsylvania. Institutional review board (IRB) approval and authorization for data sharing were obtained from both participating universities. As the only record linking the participant and the research was the informed consent document, the IRBs waived the requirement for written informed consent. Each participant received a letter of information outlining the study, and completion of the survey was taken as the form of consent to participate.

\section{Recruitment}

Recruitment sites included outpatient clinics, inpatient units, and community support groups. Participants were recruited during a routine visit to an outpatient stroke clinic within the Texas Medical Center (Houston, TX). The outpatient stroke clinic manages care of racially and ethnically diverse stroke survivors and treated approximately 1000 new stroke survivors in 2019. Participants were also recruited at an annual Houston community stroke festival and 2 Houston-area stroke support groups to supplement recruitment. In Philadelphia, Pennsylvania, participants were recruited from a comprehensive stroke center (CSC) and affiliated outpatient stroke clinic. The CSC serves a diverse minority and medically underserved population and treated approximately 600 patients with acute stroke in 2019. Screening measures to determine eligibility criteria included accessing electronic health records and participant self-reports. Identifiers (eg, names) collected for approaching potential participants were not retained.

Eligibility criteria for patients from both participating universities were as follows: patients who (1) were aged $\geq 18$ years, (2) spoke and read English or Spanish, and (3) had a 
history of stroke or self-identified as an informal caregiver of a stroke survivor. In Houston, surveys were collected in person using an Apple iPad and Research Electronic Data Capture (REDCap) [25,26] survey links or paper surveys and manually entered into REDCap [25,26] by a trained research member. Surveys with the survey links were also emailed or completed by telephonic interviews by a trained research member who manually entered the data into REDCap [25,26]. Surveys were carried out from September 2018 to July 2019. In Philadelphia, in-person surveys were collected directly via REDCap $[25,26]$ survey links on an iPad. Surveys were carried out from March 2019 to July 2019. All surveys were assigned a study identifier without personal identifiers. The mode of data collection was dependent on user comfort and iPad availability. All data were collected when trained surveyors were available, except for the Houston site, which also emailed REDCap [25,26] survey links for participants to complete. REDCap [25,26] is a secure, web-based app that supports data capture and export procedures at both universities.

\section{Variables}

The survey was not intended to collect psychometric data and thus did not rely on a validated psychometric instrument. However, contributions from experts in neurology, nursing, and bioinformatics were used to create a 14-question survey in English and Spanish languages (Multimedia Appendix 1). In total, 8 demographic questions included variables such as gender, race, ethnicity, and health insurance status. The duration in months from stroke events for stroke survivors and relationship (eg, spouse) between stroke survivors and caregivers were obtained. A total of 6 internet access and usage questions included an inquiry into the form of internet access at home, including cellular phone data as well as types of devices used to access the internet. Modes of communication, including email, text messages, web browsing, and gaming interactions, were included as discrete queries. Time spent and the language predominately used while on a device used to access the internet were separated for choice.

\section{Statistical Analysis}

Data were analyzed using SPSS 25.0. Participants who selected being both stroke survivors and caregivers were counted as stroke survivors for the analysis. Descriptive data were generated to explore trends in internet access and usage through cross-tabulation. Comparisons with categorical data were done using the chi-square test, whereas the Mann-Whitney U test was used for comparisons involving ordinal variables. On the basis of a sample size of 127 , a one-sample chi-square test had $80 \%$ power when the hypothesized proportion of internet users was 0.9 , and the proportion of internet users in the sampled population was 0.8 [27]. As we planned to test this hypothesis in both stroke survivors and caregivers, we recruited 248 stroke survivors and 127 caregivers.

\section{Results}

\section{Sample Characteristics of Stroke Survivors and Informal Caregivers}

Of the 397 surveys collected, 375 were analyzed (Table 1). Overall, 22 surveys were excluded because 19 participants did not indicate stroke survivors or caregiver status, and 3 participants did not complete the internet access and usage questions. Of the 375 surveys, $248(66.1 \%)$ were from stroke survivors and $127(33.9 \%)$ were from caregivers. Overall, $45.3 \%$ $(169 / 373)$ of the participants were male, and $89.4 \%(329 / 368)$ reported having health insurance. Most participants (54/127, $42.5 \%$ ) reported a spousal caregiver relationship to the care recipient, followed by a child caregiver relationship (39/127, $30.7 \%)$ to the parent care recipient. Participants (318/375, $84.8 \%$ ) were primarily recruited from outpatient sites. A total of 107 of the 375 (28.5\%) participants surveyed were from Philadelphia sites, including 58 (54.2\%) from inpatient units and $49(45.8 \%)$ from an outpatient clinic. 
Table 1. Comparison of demographic characteristics of stroke survivors and informal caregivers $(\mathrm{N}=375)$ by internet access.

\begin{tabular}{|c|c|c|c|c|c|}
\hline \multirow[t]{2}{*}{ Characteristics } & \multirow[t]{2}{*}{ Total participants ${ }^{\mathrm{a}}$} & \multicolumn{2}{|c|}{ With internet access ${ }^{b}(n=323,86.1 \%)$} & \multicolumn{2}{|c|}{ Without internet access ${ }^{\mathrm{b}}(\mathrm{n}=52,14 \%)$} \\
\hline & & $\begin{array}{l}\text { Informal caregivers } \\
(\mathrm{n}=123)\end{array}$ & $\begin{array}{l}\text { Stroke survivors } \\
(\mathrm{n}=200)\end{array}$ & $\begin{array}{l}\text { Informal caregivers } \\
(\mathrm{n}=4)\end{array}$ & $\begin{array}{l}\text { Stroke survivors } \\
(\mathrm{n}=48)\end{array}$ \\
\hline Age (years), mean (SD) & 58 & $51(14)$ & $59(14)$ & $60(19)$ & $69(12)$ \\
\hline Sex (male), n (\%) & $169(45.3)$ & $33(26.8)$ & $108(54.3)$ & $1(25)$ & $27(57.4)$ \\
\hline Health insurance, n (\%) & $329(89.4)$ & $100(82)$ & $185(94.9)$ & $4(100)$ & $40(85)$ \\
\hline \multicolumn{6}{|l|}{ Race and ethnicity, n (\%) } \\
\hline Non-Hispanic Black & $132(35.3)$ & $35(29)$ & $71(36)$ & $1(33)$ & $25(52)$ \\
\hline Non-Hispanic White & $114(30.4)$ & $48(39)$ & $63(32)$ & $-^{c}$ & $3(6)$ \\
\hline Hispanic & $91(24)$ & $31(25)$ & $44(22)$ & $2(67)$ & $14(29)$ \\
\hline Other & $37(10)$ & $9(7)$ & $22(11)$ & - & $6(13)$ \\
\hline \multicolumn{6}{|c|}{ Time since stroke (months), n (\%) } \\
\hline$<3$ & $73(30)$ & - & $48(24)$ & - & $25(57)$ \\
\hline $3-6$ & $33(14)$ & - & $28(14)$ & - & $5(11)$ \\
\hline $6-12$ & $33(14)$ & - & $29(15)$ & - & $4(9)$ \\
\hline$>12$ & $102(42.3)$ & - & $92(47)$ & - & $10(23)$ \\
\hline \multicolumn{6}{|l|}{ Relationship $^{\mathrm{d}}, \mathbf{n}(\%)$} \\
\hline Parent & $11(9)$ & $9(7)$ & - & $2(50)$ & - \\
\hline Spouse & $54(43)$ & $52(42)$ & - & $2(50)$ & - \\
\hline Son or daughter & $39(31)$ & $39(32)$ & - & - & - \\
\hline Sibling & $6(5)$ & $6(5)$ & - & - & - \\
\hline Grandchild & $4(3)$ & $4(3)$ & - & - & - \\
\hline Friend & $13(11)$ & $13(11)$ & - & - & - \\
\hline
\end{tabular}

${ }^{\mathrm{a}}$ Values in this column represent the number of participants who answered the specific demographic survey item.

${ }^{\mathrm{b}}$ Counts may not add up to the $\mathrm{n}$ value indicated in the column header because of missing data. Percentages may not add up to $100 \%$ because of rounding off.

${ }^{\mathrm{c}}$ Not available.

${ }^{\mathrm{d}}$ Caregiver's relationship with the care recipient.

Stroke survivors with internet access were younger (mean 59, SD 14 years) than stroke survivors without internet access (mean 69 , SD 12 years). Similarly, caregivers with internet access were younger (51, SD 14 years) than those without internet access (mean 60, SD 19 years). Overall, 36.4\% (71/197) non-Hispanic Black, 31.9\% (63/197) non-Hispanic White, and 22.3\% (44/197) Hispanic stroke survivors reported internet access. Fifty two percent (25/48) non-Hispanic Black, 6.2\% (3/48) non-Hispanic White, and $29.1 \%$ (14/48) Hispanic stroke survivors reported no internet access. Of those that reported internet access, $28.5 \%$ (35/123) non-Hispanic Black, 39\% (48/123) non-Hispanic White, and 25.2\% (31/123) Hispanic caregivers reported internet access. One $(1 / 3,33 \%)$ non-Hispanic Black and two $(2 / 3,67 \%)$ Hispanic caregivers reported no internet access. More stroke survivors with stroke events $>12$ months ago $(n=197)$ had internet access as compared with those with stroke events $<3$ months ago $(n=44)$. The difference in internet access between these 2 groups of stroke survivors was statistically significant $(U=2782.0, z=-3.93, P<.001)$.

\section{Characteristics of Stroke Survivor and Informal Caregiver Internet Users}

Overall, $86.1 \%(323 / 375)$ of participants reported internet access (Table 2). Compared with an estimate that $89 \%$ of American adults have internet access $[27,28], 80.6 \%(200 / 248)$ of stroke survivors $(P<.001)$ and $96.8 \%(123 / 127)$ of caregivers $(P=.001)$ had access. Caregivers were more likely than stroke survivors to access the internet $\left(\mathrm{N}=375, \chi^{2}{ }_{1}=18.5, P<.001\right)$. Smartphones were the most common type of device used to access the internet. Of the stroke survivors, $82.5 \%$ (165/200) reported using a smartphone, $59.5 \%$ (119/200) reported using a computer, and $40.5 \%(81 / 200)$ reported using an iPad to access the internet. Similarly, 91.1\% (112/123) caregivers reported using a smartphone, 78\% (96/123) reported using a computer, and $57.7 \%(71 / 123)$ reported using an iPad to access the internet. Email was the most common type of internet usage reported among stroke survivors $(143 / 200,71.2 \%)$ and caregivers $(110 / 123,89.4 \%)$, followed by browsing the web (stroke survivors $=122 / 200,61 \%$; caregivers $=104 / 123,84.6 \%$ ) and video games (stroke survivors $=40 / 200,20 \%$; caregivers $=42 / 123$, 
$34.1 \%)$. The number of hours per week spent using the internet by caregivers $(n=122)$ was higher than that of stroke survivors $(\mathrm{n}=194)$, and the difference was statistically significant ( $U=8922.00, z=-3.81, P<.001)$. The majority of stroke survivors
$(177 / 200,88.5 \%)$ and caregivers $(116 / 123,94.3 \%)$ reported English as the primary language used in their devices. Caregivers were more likely to use text messaging than stroke survivors $\left(\mathrm{n}=321, \chi_{1}^{2}=14.74, P<.001\right)$.

Table 2. Internet usage characteristics of stroke survivors and informal caregivers.

\begin{tabular}{|c|c|c|}
\hline \multirow[t]{2}{*}{ Internet usage characteristics } & \multicolumn{2}{|c|}{ Total participants with internet access ${ }^{\mathrm{a}}(\mathrm{n}=323)$} \\
\hline & Informal caregivers $(\mathrm{n}=123)$ & Stroke survivors $(\mathrm{n}=200)$ \\
\hline \multicolumn{3}{|l|}{ Type of device, $n(\%)$} \\
\hline Smartphone & $112(91.1)$ & $165(82.5)$ \\
\hline Computer & $96(78)$ & $119(59.5)$ \\
\hline iPad or tablet & $71(58)$ & $81(40.5)$ \\
\hline Other & $8(7)$ & $8(4)$ \\
\hline Do not access the internet ${ }^{\mathrm{b}}$ & $-^{c}$ & $4(2)$ \\
\hline \multicolumn{3}{|l|}{ Internet usage, $\mathrm{n}(\%)$} \\
\hline Email & $110(89.4)$ & $143(71.2)$ \\
\hline Web pages & $104(84.6)$ & $122(61)$ \\
\hline Video games & $42(34)$ & $40(20)$ \\
\hline Other & $30(24)$ & $40(20)$ \\
\hline Do not access the internet ${ }^{b}$ & $1(1)$ & $23(12)$ \\
\hline \multicolumn{3}{|c|}{ Internet hours per week (hours), n (\%) } \\
\hline $0-5$ & $27(22)$ & $87(45)$ \\
\hline $6-10$ & $28(23)$ & $38(20)$ \\
\hline $11-15$ & $25(20)$ & $25(13)$ \\
\hline $16-20$ & $14(12)$ & $13(7)$ \\
\hline $21-25$ & $6(5)$ & $5(3)$ \\
\hline$>25$ & $22(18)$ & $26(13)$ \\
\hline \multicolumn{3}{|l|}{ Device language used, $n(\%)$} \\
\hline English & $116(94.3)$ & $177(88.5)$ \\
\hline Spanish & $14(11)$ & $25(12.5)$ \\
\hline Other & $4(3)$ & $6(3)$ \\
\hline \multicolumn{3}{|l|}{ Text messaging } \\
\hline Yes, n (\%) & 104 (84.6) & $121(60.5)$ \\
\hline
\end{tabular}

${ }^{\mathrm{a}}$ Counts may not add up to the $\mathrm{n}$ values indicated in the column header because of missing data. Percentages may not add up to $100 \%$ because of rounding off.

${ }^{\mathrm{b}}$ Home internet access is available but does not personally access the internet from home.

${ }^{\mathrm{c}}$ Not available.

\section{Discussion}

\section{Principal Findings}

Overall, most of the sampled stroke population reported having internet access. Compared with a national estimate of adults with internet access, fewer stroke survivors reported internet access, whereas a greater number of caregivers reported access. Caregivers were more likely to access the internet and spend more time per week using the internet than stroke survivors. Stroke survivors and caregivers with internet access were younger than those without internet access. Internet access was significantly higher in stroke survivors more than 12 months after stroke than in stroke survivors less than 3 months after stroke. Smartphones were the most common devices used to access the internet.

\section{Comparison With Prior Work}

Overall, 85\% (323/375) of the participants reported internet access, which is lower than that of the general public [27,29], but higher than the $72 \%$ for US adult internet users living within 
the confines of a chronic condition [30]. Similar to our findings, mobile devices and computers are commonly used platforms [31] for accessing the internet and may be feasible and acceptable platforms for providing web-based stroke recovery interventions. Optimizing web-based interventions to be accessible by smartphones and computers may increase accessibility, given the predominance of smartphone and computer access among this sample. Lesser internet technology use among aging patients and their caregivers compared with younger adults [30] may indicate that these platforms may be challenging for the older stroke population. However, stroke is no longer a chronic condition in older individuals alone. The increasing rates (men $41.5 \%$ and women $30 \%$, aged $35-44$ years) of acute ischemic stroke from 2003 to 2012 in young adults coexist with the increasing prevalence of traditional risk factors $[32,33]$ and emphasize the importance of focusing on web-based stroke recovery efforts in younger adults. Ischemic stroke events have increased significantly in adults aged 18-54 years [32]. Furthermore, the perception of the digital divide based on advancing age is rapidly changing, as internet use becomes more pervasive in the United States. Adults in the United States are reporting internet usage during the COVID-19 pandemic, with $84 \%$ of individuals aged $\geq 50$ years, $98 \%$ of individuals aged $30-49$ years, and $100 \%$ of individuals aged 18-29 years of age reporting internet usage or owning a smartphone device [34]. It is likely that web-based approaches will become more feasible and acceptable with the changing exposures and needs of technologically diverse stroke populations.

Chronic stroke survivors (stroke event $>12$ months ago) reported the highest rates of internet access, whereas those less than 3 months poststroke had the least access. This suggests that access and ease of internet use may be more robust in chronic poststroke care. Web-based stroke recovery interventions may require personalized strategies for stroke survivors' recovery status and individual preferences [15]. Stroke recovery care may also be limited by physical and geographical barriers. Although not among stroke survivors, web-based telehealth visits have been successfully used in the general population and have been shown to improve blood pressure control in hypertensive patients [35]. These web-based visits may be used as a platform to capture poststroke patient-reported outcomes and implement interventions centered on secondary stroke prevention, such as risk factor control, medication adherence, and lifestyle modifications. The COVID-19 pandemic has highlighted the utility of web-based telehealth visits. For example, the rapid transition to telehealth visits for outpatient care among patients with neurological diseases has been implemented, allowing patients to communicate with health care providers via smartphones and other devices [36]. As web-based telehealth services expand, health care professionals are likely to learn more about the feasibility and accessibility of these web-based services across different populations with incentivization to assemble infrastructures for effective implementation of web-based poststroke care.

Because most stroke survivors are discharged home from the hospital, many only receive care from unprepared caregivers [37]. The amount of care provided by the caregiver to the stroke survivor appears to increase significantly immediately after hospital discharge and remains high throughout the first 12 months after the stroke [38]. Web-based interventions that actively engage caregivers may improve postacute stroke care. Caregivers were more likely to access the internet and spend more time using on it than stroke survivors. Caregivers of individuals with chronic conditions appear to use the internet for general purposes, to access health-related information and track health-related indicators (eg, weight), support, and services [30,31]. Caring for individuals with a chronic condition is considered a major life stressor that negatively affects the health and well-being of caregivers [39-42]. However, stroke survivor-informal caregiver dyad interventions have predominately focused on the health and well-being of stroke survivors rather than caring for oneself as a caregiver [40]. Although more studies are needed to determine the effectiveness of web-based interventions aimed at meeting the needs of caregivers [40,43], the American Heart Association or American Stroke Association recommends web-based stroke recovery interventions that meet the evolving needs of technologically advanced caregivers of stroke survivors [40]. Optimal stroke recovery requires web-based strategies that target the health and well-being of both stroke survivors and caregivers, with both being active participants [40].

The highest number of participants who reported internet access were non-Hispanic Whites. Racial differences in internet access and technology usage emphasize the need to address known disparities [28]. Racial and ethnic disparities also exist in stroke recovery care. Non-Hispanic Black and Hispanic participants receive less intensive stroke rehabilitation, education, and counseling than non-Hispanic White participants [44,45]. Minority groups, including non-Hispanic Black and Hispanic participants, have a higher risk of stroke [3]. The highest increase in stroke prevalence was observed in Hispanic men [3]. Non-Hispanic Black participants have a higher prevalence of uncontrolled blood pressure, which is the most important risk factor for stroke [46]. Notably, efforts to reduce racial and ethnic disparities in blood pressure control among stroke survivors have not been effective [47]. Web-based interventions to reduce stroke recurrence and improve risk factor control could address this gap in care by providing internet services and devices to individuals from the highest risk groups. Considerations for language barriers should also be given in web-based poststroke care.

\section{Limitations}

One study limitation is that the sample may not be representative of all US stroke survivors and their informal caregivers. Therefore, the results should be interpreted with caution.

Detailed information regarding socioeconomic status and urban or rural location was not obtained. Future studies of internet access and use should consider targeted oversampling of economically disadvantaged stroke populations and stroke survivors and caregivers living in remote areas with limited broadband connectivity. Socioeconomic details can be gauged by collecting individual- and neighborhood-level social determinants of health data. Geo-mapping using ZIP codes for areas with the highest socioeconomic disparities and geographic barriers to classify the type and range of web-based services 
rendered will be useful before system-wide implementation of web-based stroke recovery interventions. The sample size was adequate, and the sample was racially and ethnically diverse; however, the nonprobability convenience sampling strategy may have resulted in selection bias. Stroke survivors and caregivers not surveyed were likely missed at random because efforts were limited to surveyor availability. Furthermore, the generalizability of the results is limited by the lack of nonparticipant data (eg, demographics and reasons). However, the sample came from 2 large urban areas providing data from considerably underinvestigated minority stroke survivor and caregiver populations. Although the survey was developed and edited by a multidisciplinary team, the internal consistency and content validity of the survey were not tested.

\section{Conclusions}

Web-based interventions following stroke should consider the role of the caregiver, participant age, race, ethnicity, the use of smartphone apps, email and text correspondence, and the amount of time since the stroke event. The results suggest that web-based interventions may be feasible and acceptable for certain stroke survivors and caregivers. Future feasibility and acceptability studies should consider these findings when designing and implementing web-based stroke recovery interventions to minimize barriers to access, tailor the intervention to maximize adherence, and target those most likely to use web-based resources.

\section{Acknowledgments}

The authors acknowledge and thoughtfully thank the University of Texas Health Science Center at Houston (UTHealth) Neurology Clinic, UTHealth Cizik School of Nursing, especially Tina Varughese, RN, and Andrea Ancer Leal, RN-BSN, LMSW, West Houston Stroke Warriors, Houston Aphasia Recovery Center, UTHealth Stomp Out Stroke Festival, Temple University Hospital Neurology Clinic staff, and all participating stroke survivors and informal caregivers. This work was supported by NIH/NCATS grants UL1 TR000445 and UL1 TR001105. UTHealth study data were collected and managed using REDCap hosted at the University of Texas School of Biomedical Informatics at Houston.

\section{Authors' Contributions}

IAN contributed to data curation; formal analysis; investigation; project administration; resources; software; validation; and writing, reviewing, and editing the manuscript. TCM contributed to software; writing, reviewing, and editing the manuscript; visualization; and project administration. YB contributed to data curation, software, and visualization. NH and MO contributed to data curation. CJ reviewed and edited the manuscript and contributed to survey development. MGW contributed to supervision and reviewed and edited the manuscript. SS contributed to supervision, reviewing and editing the article, and survey development. AS contributed to investigation, validation, supervision, reviewing and editing the manuscript, and survey development. JESB contributed to conceptualization, methodology, investigation, validation, supervision, reviewing and editing the manuscript, and survey development.

\section{Conflicts of Interest}

None declared.

\section{Multimedia Appendix 1}

Internet Usage Survey Questions. [DOCX File, 19 KB-Multimedia Appendix 1]

\section{References}

1. Virani SS, Alonso A, Benjamin EJ, Bittencourt MS, Callaway CW, Carson AP, et al. Heart Disease and Stroke Statistics-2020 Update: A Report From the American Heart Association. Circulation 2020 Mar 03;141(9) [FREE Full text] [doi: 10.1161/CIR.0000000000000757]

2. Published January 9, 2019. Stroke Fact Sheet|Data \& Statistics|DHDSP|CDC. URL: https://www.cdc.gov/dhdsp/data statistics/ fact sheets/fs stroke.htm [accessed 2019-10-30]

3. Benjamin EJ, Muntner P, Alonso A, Bittencourt MS, Callaway CW, Carson AP, et al. Heart Disease and Stroke Statistics-2019 Update: A Report From the American Heart Association. Circulation 2019 Mar 05;139(10). [doi: 10.1161/CIR.0000000000000659]

4. National Aphasia Association. Aphasia FAQs. URL: https://www.aphasia.org/aphasia-faqs/ [accessed 2020-10-12]

5. Hackett M, Pickles K. Part I: frequency of depression after stroke: an updated systematic review and meta-analysis of observational studies. Int J Stroke 2014 Dec;9(8):1017-1025. [doi: 10.1111/ijs.12357] [Medline: 25117911]

6. Rafsten L, Danielsson A, Sunnerhagen K. Anxiety after stroke: A systematic review and meta-analysis. J Rehabil Med 2018 Sep 28;50(9):769-778 [FREE Full text] [doi: 10.2340/16501977-2384] [Medline: 30184240]

7. Sanner Beauchamp JE, Casameni Montiel T, Cai C, Tallavajhula S, Hinojosa E, Okpala MN, et al. A Retrospective Study to Identify Novel Factors Associated with Post-stroke Anxiety. Journal of Stroke and Cerebrovascular Diseases 2020 Feb;29(2):104582. [doi: 10.1016/j.jstrokecerebrovasdis.2019.104582] 
8. Cumming TB, Marshall RS, Lazar RM. Stroke, Cognitive Deficits, and Rehabilitation: Still an Incomplete Picture. International Journal of Stroke 2012 Dec 24;8(1):38-45. [doi: 10.1111/j.1747-4949.2012.00972.x]

9. Mijajlović MD, Pavlović A, Brainin M, Heiss W, Quinn TJ, Ihle-Hansen HB, et al. Post-stroke dementia - a comprehensive review. BMC Med 2017 Jan 18;15(1). [doi: 10.1186/s12916-017-0779-7]

10. Padberg I, Hotter B, Liebenau A, Knispel P, Lehnerer S, Heel S, et al. <p>Unmet Need for Social and Emotional Support and Lack of Recalled Screening Is Associated with Depression in the Long-Term Course After Stroke</p>. RMHP 2020 Apr;Volume 13:285-293. [doi: 10.2147/rmhp.s228265]

11. BergstrÃ $\mathbb{m}$ A, Koch L, Andersson M, Tham K, Eriksson G. Participation in everyday life and life satisfaction in persons with stroke and their caregivers 3â€" 6 months after onset. J Rehabil Med 2015 Jun;47(6):508-515. [doi: 10.2340/16501977-1964]

12. LA Health. 2019. URL: http://publichealth.lacounty.gov/ha/reports/habriefs/2007/Caregiving Final.pdf [accessed 2019-10-25]

13. Redfern J, McKevitt C, Wolfe CD. Development of Complex Interventions in Stroke Care. Stroke 2006 Sep;37(9):2410-2419. [doi: 10.1161/01.str.0000237097.00342.a9]

14. Almallouhi E, Al Kasab S, Harvey J, Simpson KN, Turner N, Debenham E, et al. Teleneurology Network to Improve Access to Neurologists for Patients in Rural Areas: A Real-World Experience. Telemed J E Health 2020 Jan;26(1):110-113. [doi: 10.1089/tmj.2018.0290] [Medline: 30762494]

15. Pugliese M, Ramsay T, Johnson D, Dowlatshahi D. Mobile tablet-based therapies following stroke: A systematic scoping review of administrative methods and patient experiences. PLoS One 2018;13(1):e0191566 [FREE Full text] [doi: 10.1371/journal.pone.0191566] [Medline: 29360872]

16. Goldberg LR, Bell E, King C, O’Mara C, McInerney F, Robinson A, et al. Relationship between participants' level of education and engagement in their completion of the Understanding Dementia Massive Open Online Course. BMC Med Educ 2015 Mar 26;15(1). [doi: 10.1186/s12909-015-0344-z]

17. Grant RW, Cagliero E, Chueh HC, Meigs JB. Internet use among primary care patients with type 2 diabetes. J Gen Intern Med 2005 May;20(5):470-473. [doi: 10.1111/j.1525-1497.2005.04239.x]

18. Hatcher-Martin JM, Adams JL, Anderson ER, Bove R, Burrus TM, Chehrenama M, et al. Telemedicine in neurology. Neurology 2019 Dec 04;94(1):30-38. [doi: 10.1212/wnl.0000000000008708]

19. Kim DY, Kwon H, Nam K, Lee Y, Kwon H, Chung YS. Remote Management of Poststroke Patients With a Smartphone-Based Management System Integrated in Clinical Care: Prospective, Nonrandomized, Interventional Study. J Med Internet Res 2020 Feb 27;22(2):e15377. [doi: 10.2196/15377]

20. Anderson M, Perrin A. Technology use among seniors. Pew Research Center; Internet \& Technology. URL: https://www. pewresearch.org/internet/2017/05/17/technology-use-among-seniors/ [accessed 2020-09-25]

21. Yousufuddin M, Young N. Aging and ischemic stroke. Aging 2019 May 01;11(9):2542-2544. [doi: 10.18632/aging.101931]

22. Russo T, Felzani G, Marini C. Stroke in the very old: a systematic review of studies on incidence, outcome, and resource use. J Aging Res 2011;2011:108785 [FREE Full text] [doi: 10.4061/2011/108785] [Medline: 21876804]

23. Perrin A, Turner E. Smartphones help blacks, Hispanics bridge some but not all digital gaps with whites. Pew Research Center. URL: https://www.pewresearch.org/fact-tank/2019/08/20/ smartphones-help-blacks-hispanics-bridge-some-but-not-all-digital-gaps-with-whites/ [accessed 2020-10-06]

24. Cruz-Flores S, Rabinstein A, Biller J, Elkind MSV, Griffith P, Gorelick PB, American Heart Association Stroke Council, Council on Cardiovascular Nursing, Council on Epidemiology Prevention, Council on Quality of CareOutcomes Research. Racial-ethnic disparities in stroke care: the American experience: a statement for healthcare professionals from the American Heart Association/American Stroke Association. Stroke 2011 Jul;42(7):2091-2116. [doi: 10.1161/STR.0b013e3182213e24] [Medline: 21617147]

25. Harris PA, Taylor R, Thielke R, Payne J, Gonzalez N, Conde JG. Research electronic data capture (REDCap)--a metadata-driven methodology and workflow process for providing translational research informatics support. J Biomed Inform 2009 Apr;42(2):377-381 [FREE Full text] [doi: 10.1016/j.jbi.2008.08.010] [Medline: 18929686]

26. Harris PA, Taylor R, Minor BL, Elliott V, Fernandez M, O'Neal L, et al. The REDCap consortium: Building an international community of software platform partners. Journal of Biomedical Informatics 2019 Jul;95:103208. [doi: 10.1016/j.jbi.2019.103208]

27. Anderson M, Perrin A, Jiang J. Some Americans don't use the internet. Who are they?. URL: http://www.pewresearch.org/ fact-tank/2018/03/05/some-americans-dont-use-the-internet-who-are-they/ [accessed 2018-09-17]

28. Demographics of internet and home broadband usage in the United States. URL: https://www.pewresearch.org/internet/ fact-sheet/internet-broadband/ [accessed 2020-04-27]

29. The Diagnosis Difference. URL: https://www.pewresearch.org/science/2013/11/26/the-diagnosis-difference/ [accessed 2020-10-16]

30. Shaffer K, Chow P, Cohn W, Ingersoll KS, Ritterband LM. Informal Caregivers' Use of Internet-Based Health Resources: An Analysis of the Health Information National Trends Survey. JMIR Aging 2018 Dec 18;1(2):e11051 [FREE Full text] [doi: 10.2196/11051] [Medline: 31518244]

31. Fox S, Duggan M, Purcell K. Family caregivers are wired for health. Pew Research Center: Internet, Science \& Tech. URL: https://www.pewresearch.org/internet/2013/06/20/family-caregivers-are-wired-for-health/ [accessed 2020-10-16] 
32. George MG, Tong X, Bowman BA. Prevalence of Cardiovascular Risk Factors and Strokes in Younger Adults. JAMA Neurol 2017 Jun 01;74(6):695. [doi: 10.1001/jamaneurol.2017.0020]

33. George MG. Risk Factors for Ischemic Stroke in Younger Adults. Stroke 2020 Mar;51(3):729-735. [doi: 10.1161/strokeaha.119.024156]

34. Schumacher S, Kent N. 2020. 8 charts on internet use around the world as countries grapple with COVID-19. URL: https:/ /www.pewresearch.org/fact-tank/2020/04/02/8-charts-on-internet-use-around-the-world-as-countries-grapple-with-covid-19/ [accessed 2020-10-16]

35. Chen M, Chen K, Chiang S, Daimon M, Lee J, Yu EW, et al. A telehealth service model for the treatment of hypertension. J Telemed Telecare 2013 Jul;19(5):238-241. [doi: 10.1177/1357633X13495476] [Medline: 24163232]

36. Al Kasab S, Almallouhi E, Holmstedt CA. Optimizing the Use Of Teleneurology During the COVID-19 Pandemic. Telemedicine and e-Health 2020 Oct 01;26(10):1197-1198. [doi: 10.1089/tmj.2020.0109]

37. Joo H, Dunet DO, Fang J, Wang G. Cost of informal caregiving associated with stroke among the elderly in the United States. Neurology 2014 Oct 10;83(20):1831-1837. [doi: 10.1212/wnl.0000000000000986]

38. Olai L, Borgquist L, Svärdsudd K. Life situations and the care burden for stroke patients and their informal caregivers in a prospective cohort study. Upsala Journal of Medical Sciences 2015 Jun 14;120(4):290-298. [doi: $10.3109 / 03009734.2015 .1049388]$

39. Schulz R, Tompkins C. Informal caregivers in the United States: prevalence, caregiver characteristics, and ability to provide care. https://www.ncbi.nlm.nih.gov/books/NBK210048/: National Research Council (US) Committee on the Role of Human Factors in Home Health Care; 2010.

40. Bakas T, McCarthy M, Miller ET. Update on the State of the Evidence for Stroke Family Caregiver and Dyad Interventions. Stroke 2017 May;48(5). [doi: 10.1161/strokeaha.117.016052]

41. Cameron JI, Naglie G, Green TL, Gignac MA, Bayley M, Huijbregts M, et al. A feasibility and pilot randomized controlled trial of the "Timing it Right Stroke Family Support Program". Clin Rehabil 2014 Dec 31;29(11):1129-1140. [doi: $10.1177 / 0269215514564897]$

42. Achilike S, Beauchamp J, Cron S, Okpala M, Payen SS, Baldridge L, et al. Caregiver Burden and Associated Factors Among Informal Caregivers of Stroke Survivors. J Neurosci Nurs 2020 Dec;52(6):277-283. [doi: 10.1097/JNN.0000000000000552] [Medline: 33156591]

43. Hopwood J, Walker N, McDonagh L, Rait G, Walters K, Iliffe S, et al. Internet-Based Interventions Aimed at Supporting Family Caregivers of People With Dementia: Systematic Review. J Med Internet Res 2018 Jun 12;20(6):e216. [doi: 10.2196/jmir.9548]

44. Morgenstern LB, Sais E, Fuentes M, Ifejika NL, Jiang X, Horn SD, et al. Mexican Americans receive less intensive stroke rehabilitation than non-hispanic whites. Stroke 2017 Jun;48(6):1685-1687. [doi: 10.1161/strokeaha.117.016931]

45. Jacobs BS, Birbeck G, Mullard AJ, Hickenbottom S, Kothari R, Roberts S, et al. Quality of hospital care in African American and white patients with ischemic stroke and TIA. Neurology 2006 Mar 27;66(6):809-814. [doi:

10.1212/01.wnl.0000203335.45804.72]

46. Sacco RL, Boden-Albala B, Gan R, Chen X, Kargman DE, Shea S, et al. Stroke incidence among white, black, and hispanic residents of an urban community: the northern manhattan stroke study. Am J Epidemol 1998 Feb 1;147(3):259-268. [doi: 10.1093/oxfordjournals.aje.a009445]

47. Bridgwood B, Lager K, Mistri A. Interventions for improving modifiable risk factor control in the secondary prevention of stroke. Cochrane Database Syst Rev 2018;5. [doi: 10.1002/14651858.CD009103.pub3]

\section{Abbreviations}

CSC: comprehensive stroke center

IRB: institutional review board

REDCap: Research Electronic Data Capture

Edited by G Eysenbach; submitted 19.10.20; peer-reviewed by $R$ Watson, P Tremoulet; comments to author 26.12.20; revised version
received 05.01.21; accepted 17.01.21; published 08.03.21
Please cite as:
Naqvi IA, Montiel TC, Bittar Y, Hunter N, Okpala M, Johnson C, Weiner MG, Savitz, S, Sharrief A, Beauchamp JES
Internet Access and Usage Among Stroke Survivors and Their Informal Caregivers: Cross-sectional Study
JMIR Form Res $2021 ; 5(3):$ e25123
URL: $\underline{\text { https://formative.jmir.org/2021/3/e25123 }}$
doi: $\underline{10.2196 / 25123}$
PMID: $\underline{3683206}$


CImama Ali Naqvi, Tahani Casameni Montiel, Yazan Bittar, Norma Hunter, Munachi Okpala, Constance Johnson, Mark G Weiner, Sean Savitz, Anjail Sharrief, Jennifer Elizabeth Sanner Beauchamp. Originally published in JMIR Formative Research (http://formative.jmir.org), 08.03.2021. This is an open-access article distributed under the terms of the Creative Commons Attribution License (https://creativecommons.org/licenses/by/4.0/), which permits unrestricted use, distribution, and reproduction in any medium, provided the original work, first published in JMIR Formative Research, is properly cited. The complete bibliographic information, a link to the original publication on http://formative.jmir.org, as well as this copyright and license information must be included. 